NASA/TM-2002-211997

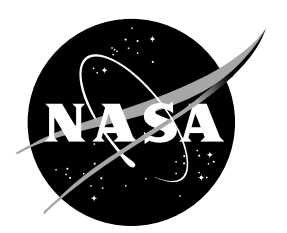

\title{
Overview of NASA Multi-Dimensional Stirling Convertor Code Development and Validation Effort
}

Roy C. Tew and James E. Cairelli

Glenn Research Center, Cleveland, Ohio

Mounir B. Ibrahim

Cleveland State University, Cleveland, Ohio

Terrence W. Simon

University of Minnesota, Minneapolis, Minnesota

David Gedeon

Gedeon Associates, Athens, Ohio 
Since its founding, NASA has been dedicated to the advancement of aeronautics and space science. The NASA Scientific and Technical Information (STI) Program Office plays a key part in helping NASA maintain this important role.

The NASA STI Program Office is operated by Langley Research Center, the Lead Center for NASA's scientific and technical information. The NASA STI Program Office provides access to the NASA STI Database, the largest collection of aeronautical and space science STI in the world. The Program Office is also NASA's institutional mechanism for disseminating the results of its research and development activities. These results are published by NASA in the NASA STI Report Series, which includes the following report types:

- $\quad$ TECHNICAL PUBLICATION. Reports of completed research or a major significant phase of research that present the results of NASA programs and include extensive data or theoretical analysis. Includes compilations of significant scientific and technical data and information deemed to be of continuing reference value. NASA's counterpart of peerreviewed formal professional papers but has less stringent limitations on manuscript length and extent of graphic presentations.

- TECHNICAL MEMORANDUM. Scientific and technical findings that are preliminary or of specialized interest, e.g., quick release reports, working papers, and bibliographies that contain minimal annotation. Does not contain extensive analysis.

- CONTRACTOR REPORT. Scientific and technical findings by NASA-sponsored contractors and grantees.
- CONFERENCE PUBLICATION. Collected papers from scientific and technical conferences, symposia, seminars, or other meetings sponsored or cosponsored by NASA.

- SPECIAL PUBLICATION. Scientific, technical, or historical information from NASA programs, projects, and missions, often concerned with subjects having substantial public interest.

- TECHNICAL TRANSLATION. Englishlanguage translations of foreign scientific and technical material pertinent to NASA's mission.

Specialized services that complement the STI Program Office's diverse offerings include creating custom thesauri, building customized databases, organizing and publishing research results ... even providing videos.

For more information about the NASA STI Program Office, see the following:

- Access the NASA STI Program Home Page at http://www.sti.nasa.gov

- E-mail your question via the Internet to help@sti.nasa.gov

- Fax your question to the NASA Access Help Desk at 301-621-0134

- Telephone the NASA Access Help Desk at 301-621-0390

- Write to:

NASA Access Help Desk

NASA Center for AeroSpace Information 7121 Standard Drive

Hanover, MD 21076 
NASA/TM-2002-211997

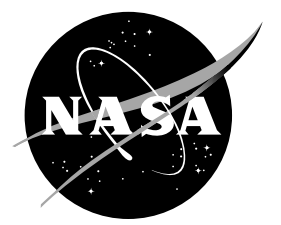

\section{Overview of NASA Multi-Dimensional Stirling Convertor Code Development and Validation Effort}

Roy C. Tew and James E. Cairelli

Glenn Research Center, Cleveland, Ohio

Mounir B. Ibrahim

Cleveland State University, Cleveland, Ohio

Terrence W. Simon

University of Minnesota, Minneapolis, Minnesota

David Gedeon

Gedeon Associates, Athens, Ohio

Prepared for the

Space Technology and Applications International Forum (STAIF-2003)

cosponsored by the American Institute of Aeronautics and Astronautics and the University of New Mexico

Albuquerque, New Mexico, February 2-6, 2003

National Aeronautics and

Space Administration

Glenn Research Center 


\section{Acknowledgments}

We would like to acknowledge the support for the work reported here that was received from Code R of NASA Headquarters.
Trade names or manufacturers' names are used in this report for identification only. This usage does not constitute an official endorsement, either expressed or implied, by the National Aeronautics and Space Administration.

Available from

NASA Center for Aerospace Information 7121 Standard Drive

Hanover, MD 21076
National Technical Information Service 5285 Port Royal Road Springfield, VA 22100

Available electronically at http:/ /gltrs.grc.nasa.gov 


\title{
Overview of NASA Multi-Dimensional Stirling Convertor Code Development and Validation Effort
}

\author{
Roy C. Tew and James E. Cairelli \\ National Aeronautics and Space Administration \\ Glenn Research Center \\ Cleveland, Ohio 44135 \\ Phone: 216-433-8471, Email: Roy.Tew@grc.nasa.gov \\ Mounir B. Ibrahim \\ Department of Mechanical Engineering \\ Cleveland State University \\ Cleveland, Ohio 44115 \\ Terrence W. Simon \\ Department of Mechanical Engineering \\ University of Minnesota \\ Minneapolis, Minnesota 55455 \\ David Gedeon \\ Gedeon Associates \\ Athens, Ohio 45701
}

\begin{abstract}
A NASA grant has been awarded to Cleveland State University (CSU) to develop a multi-dimensional (multiD) Stirling computer code with the goals of improving loss predictions and identifying component areas for improvements. The University of Minnesota (UMN) and Gedeon Associates are teamed with CSU. Development of test rigs at UMN and CSU and validation of the code against test data are part of the effort. The one-dimensional (1-D) Stirling codes used for design and performance prediction do not rigorously model regions of the working space where abrupt changes in flow area occur (such as manifolds and other transitions between components). Certain hardware experiences have demonstrated large performance gains by varying manifolds and heat exchanger designs to improve flow distributions in the heat exchangers. 1-D codes were not able to predict these performance gains. An accurate multiD code should improve understanding of the effects of area changes along the main flow axis, sensitivity of performance to slight changes in internal geometry, and, in general, the understanding of various internal thermodynamic losses. The commercial CFD-ACE code has been chosen for development of the multi-D code. This 2-D/3-D code has highly developed pre- and post-processors, and moving boundary capability. Preliminary attempts at validation of CFD-ACE models of MIT gas spring and "two space" test rigs were encouraging. Also, CSU's simulations of the UMN oscillatingflow rig compare well with flow visualization results from UMN. A complementary Department of Energy (DOE) Regenerator Research effort is aiding in development of regenerator matrix models that will be used in the multi-D Stirling code. This paper reports on the progress and challenges of this multi-D code development effort.
\end{abstract}

\section{INTRODUCTION}

The Department of Energy (DOE), Lockheed Martin (LM), NASA Glenn Research Center (GRC) and the Stirling Technology Co. (STC) are developing a high-efficiency Stirling Radioisotope Generator (SRG) for NASA Space Science Missions. The SRG is being developed for potential multi-mission use, including the provision of electric power for unmanned Mars rovers and deep space missions. The SRG is being evaluated as a high-efficiency power source alternative to replace Radioisotope Thermoelectric Generators (RTG's). The SRG system efficiency of greater than 20 percent will reduce the required amount of radioisotope by a factor of 4 or more compared to RTG's. This significantly reduces radioisotope cost, radiological inventory, and system cost.

STC previously developed the Stirling convertor under contract to DOE and is now providing further development as a subcontractor to LM. Technology Demonstration Convertors (TDC's), operating as single units and in dynamically balanced opposed pairs, are now being tested by STC and GRC. Power outputs of 55 to 65 We and efficiencies or 25 to 28 percent have been demonstrated for TDC operating conditions of $650^{\circ} \mathrm{C}$ hot-end temperature and cold-end temperatures varying from $80^{\circ}$ to $120^{\circ} \mathrm{C}$. Lockheed Martin has been selected as the SRG System Integration Contractor. GRC is conducting an in-house technology project to assist in developing the convertor for space qualification and mission implementation (Thieme, 2002), has also initiated several advanced Stirling technology efforts and is evaluating Stirling convertors for other applications. The multi-D code development effort reported on here is one of GRC's advanced Stirling technology efforts. 
The one-dimensional (1-D) Stirling codes used for design and performance prediction do not rigorously model regions of the working space where abrupt changes in flow area occur (such as manifolds and other transitions between components). Certain hardware experiences have demonstrated large performance gains by varying manifolds and heat exchanger designs to improve flow distributions in the heat exchangers. 1-D codes were not able to predict these performance gains. An accurate multi-D code should improve understanding of the effect of area changes along the main flow axis, sensitivity of performance to slight changes in internal geometry, and, in general, the understanding of various internal thermodynamic losses.

\section{MULTI-DIMENSIONAL STIRLING CODE DEVELOPMENT AND VALIDATION}

A two-year grant to Cleveland State University (CSU) for Stirling multi-D code development and validation was awarded effective August 1, 2000 and a two year grant renewal was awarded effective August 1, 2002. The University of Minnesota (UMN) and Gedeon Associates are subcontractors. The principal investigator (PI), Mounir Ibrahim of CSU, has directed the overall effort, the multi-D code development, and preparation of CSU's Stirling Laboratory Research Engine (SLRE) test facility for code validation tests. Terrence Simon of UMN has directed the building and testing of a large scale piston/cylinder test section that allows oscillating air flow to make a 90 degree turn as it passes into a disk-shaped volume which opens to the room at its outer edge. He has also acted as a consultant to CSU in CSU's development of multi-D models. David Gedeon has acted as consultant to CSU and UMN: He used the 1-D Sage code (Gedeon, 1999) to model UMN test sections and CSU's SLRE test section to aid in their design, and designed the SLRE test section and its flow inserts. He is now working on design of a new UMN expansion head (or "180 degree turn") test section, that will roughly model the flow path from the displacer/cylinder through the heater of a "TDC like" Stirling convertor. He is helping CSU with plans for SLRE instrumentation and data acquisition, and has also guided plans for measurements and calculations of regenerator "enhanced conductivity" resulting from flow eddies within the matrix.

Much of the regenerator matrix modeling effort is being done under a complementary DOE regenerator research effort. This three year effort began Sept. 1, 2000. Ibrahim of CSU is also the PI for this effort. Other members of the team are Simon of UMN, Gedeon Associates, and GRC. A major part of this effort is large-scale, oscillatory-flow, low-frequency testing of a piston/cylinder-cooler-regenerator-heater test section at UMN. Dimensionless variables for the test were chosen based upon those of one of STC's Stirling engines. The test section is sufficiently large scale and low frequency that hot-wire anemometer measurements of dynamic temperature are being made (1) within the gas plenum between the cooler tubes and the regenerator, (2) within the matrix gas, and (3) on the matrix wires. CSU is providing CFD modeling support for the test work. Several progress reports about this DOE work have been or are being published (Niu, 2002; 2003; Ibrahim, 2002b). Results of the NASA multi-D Stirling code grant effort have been published in Ibrahim (2002a) and Adolfson (2002).

The commercial CFD-ACE code was chosen for multi-D code development. This 2-D/3-D code has highly developed pre- and post-processors and moving boundary capability. CFD-ACE's developer is the CFD Research Corporation (CFDRC) of Huntsville, AL.

\section{CFD-ACE Modeling of MIT Gas Spring and "Two-Space" Test Rigs}

CFD-ACE was used to develop 2-D axisymmetric models of MIT gas spring and "two-space" test rigs (Ibrahim, 2001). Agreement with MIT's measured dimensionless gas spring work (Kornhauser, 1989) was very good. The two-space test rig was fabricated by mounting an annular heat exchanger on top of the original gas spring (The wall boundary condition for both rigs was the constant room temperature). Wall heat transfer per unit area at positions along the annular heat exchanger was calculated and compared with MIT's data and also with previous in-house CAST (for Computer Aided Simulation of Turbulent Flow) code calculations (Tew, 2001). The CFD-ACE heat transfer per unit area over the cycle was in qualitative agreement with the data, but quantitative agreement could have been better. There was also quantitative disagreement with the CAST code calculations at most heat exchanger axial positions (But variations of heat transfer over the cycle as indicated by the test data, CFD-ACE and the CAST code all looked qualitatively similar). 
Plans are to re-visit the CFD-ACE two space test rig modeling and comparison with test rig data. Also, careful comparisons will be made between the 2-D axisymmetric CFD-ACE models and 1-D Sage models of these two test rigs. Preliminary comparisons between such models, indicated that overall energy flows as calculated by the 2-D and 1-D models were quite close for the gas spring test rig but substantially different for the two-space test rig. This is not unexpected since the flow area is uniform in the gas spring but is much different in the cylinder and heat exchanger of the two-space test rig. Since the 1-D model assumes uniform flow and cannot accurately model the effects of flow separation at changes in area, it seems likely that errors in the 1-D calculations might occur. But, at this early stage in the development of multi-D models of engines and "engine like" test rigs, it can not be automatically assumed that 2-D models of the two-space rig are more accurate than 1-D models in calculation of energy flows. One possible reason for this is that the large-eddy turbulence models used contain empirical constants and have not been "calibrated" for oscillating flows in the relatively complex Stirling geometries. Also, Sage, together with the earlier GLIMPS code, has about a decade long history of comparison with engine and oscillatingflow rig test data.

\section{Two-Dimensional Model of Stirling Convertor (or Engine/Alternator)}

CSU has developed a 2-D model of a "TDC like" CSUmod Stirling engine. The 2-D axisymmetric approximation of the 3-D geometry of interest became operational in June, 2002. The model includes the oscillating power piston and displacer, together with the variable volume compression and expansion spaces, and models of the heater, cooler and regenerator. A schematic of an early version of this model is shown in Figure 1. The initial model did not include the walls surrounding the working space. The major 2-D simplifications of the 3-D geometry of interest were: (1) In the 3-D geometry of interest, the heater and cooler have alternating rectangular fins and flow passages with long axes perpendicular to the cylinder axis. In the 2-D approximation, the radial fins and flow passages have been replaced by concentric fins and flow passages with the same axis as the Stirling cylinder; total flow area and fin cross-sectional area were maintained. It was possible by choice of the number of concentric fins and flow passages to choose a hydraulic diameter that was close to that of the original 3-D geometry. (2) Four symmetrically arranged holes in the base or "spider" supporting the displacer rod, were replaced by an annular opening in the 2-D model.

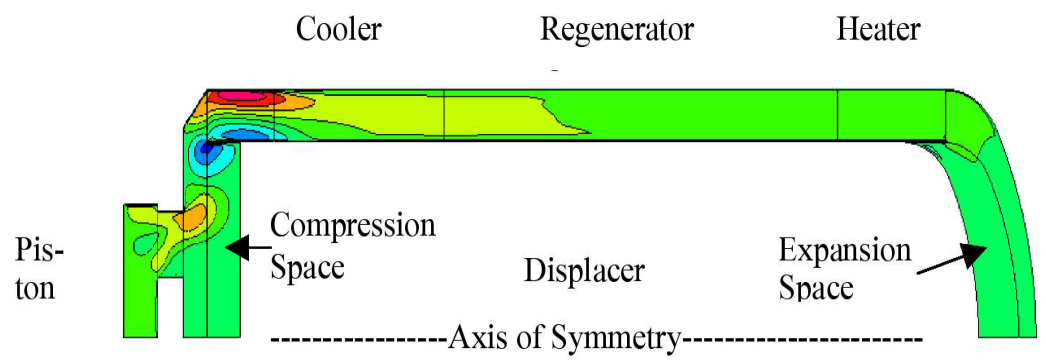

A number of modifications to the 2-D Stirling code are underway or have now been completed: (1) A model of the full pressure vessel wall has been added around the annular heater, regenerator and cooler. This will be used to study interactions between the wall temperature profile and the internal gas temperatures. (2) The surface layer of the pressure vessel wall, approximately equal to the thermal penetration

FIGURE 1. Schematic Showing U-Velocity Contours Generated by a 2-D

Axisymmetric CFD-ACE Model of a Stirling Convertor Working Space. Details of the Heat Exchanger Geometries Were Not Included in this Early Version of the Model. thickness (the thickness over which the wall temperature varies over the cycle), is being modeled around the expansion and compression spaces. Modeling the complete thickness would require additional computational time. (3) Work is underway to develop a model of the appendix gap and seal regions between the displacer and its cylinder. Shuttle and appendix gap losses result from the fluid flow and heat transfer processes that occur in this region.

\section{Progress on Three-Dimensional Model of Stirling Convertor}

An initial 3-D model of the CSUmod Stirling convertor design was set-up and run through part of an engine cycle. This permitted an estimate to be made of computing time. The previous 2-D model, on a $2 \mathrm{GHz}$ Windows workstation, required about 55 cycles over two weeks to reach a steady periodic cycle. The partial cycle 3-D run indicated that a complete run would take on the order of 1 year of computational time. This suggests the need to use a parallelized version of the CFD-ACE code on a cluster of workstations to achieve practical 3-D Stirling model computing times (a cheaper approach than use of available supercomputers). 
The basic CFD-ACE code is parallelized. CFDRC has begun parallelization of the code's grid deformation module that permits simulation of moving boundaries (pistons) and projects completion by Oct.-Nov. 2002. Also, GRC has purchased the first of 32 dual processor workstations that are to be purchased over the next three years to build a dedicated cluster. Based on CFDRC's cluster experience, it is anticipated that the completed GRC cluster should produce a computational acceleration of about 50. Thus it is hoped that a completed 3-D CFD-ACE model of a TDC or similar Stirling convertor will eventually run to "periodic steady state" on the order of 1 week.

CSU is also putting together a mini-cluster of 4 dual processor computers in FY2003. Use of the parallelized version of CFD-ACE should permit them to speed up their development runs by an acceleration factor of roughly 7 . As the larger GRC cluster develops over the three year period FY2003-2005, it will be possible for CSU to make development runs on the GRC cluster, if that proves to be advantageous to the code development effort.

\section{“90 Degree Turn” or “90 Degree Expansion Head" Experiments and CFD Modeling}

Flow visualization tests were run using a "90 degree turn" test section that replicates important features of oscillatory flows. These include large-scale separation and adverse and favorable, spatial and temporal acceleration. The geometry is a tube perpendicular to a space between two circular discs, one of which the tube penetrates such that the end of the tube is flush with the disc inner surface. The flow, driven by a piston in the tube, is oscillatory and acts on the exhaust stroke as a jet impinging on the center of a circular disc and on the intake stroke as a sink flow drawn into a tube from the space between the two discs (referred to later in the text as the "channel"). Time-varying recirculation zones and periodic appearances of highly turbulent flow were observed. In addition to a characterization of oscillatory, separating flow, these tests provided code validation support for Stirling engine design models. The project goals are to identify the areas where 1-D modeling is especially weak, provide support for developing more sophisticated design models that can be used with greater confidence, and help validate the CFD-ACE Stirling model. A more complete description of these experiments is given in Adolfson (2002).

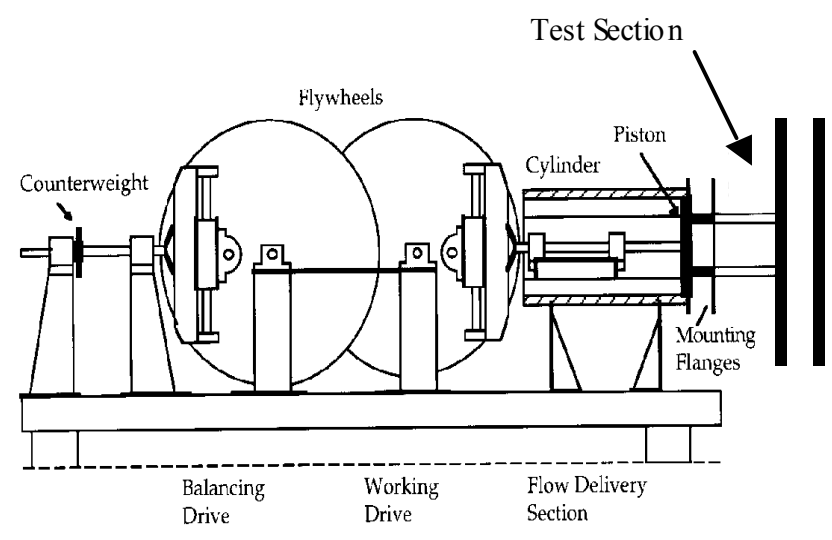

FIGURE 2. UMN Scotch Yoke Drive Facility

The test facility is shown schematically in Fig. 2. The facility uses a Scotch yoke drive system to deliver a sinusoidal piston motion. The rotational speed is continuously variable from 4.5 to 70 revolutions per minute. The test section mentioned in Fig. 2 is shown in Fig. 3. The piston diameter is 0.22 $\mathrm{m}$. The bore of the tube shown in Fig. 3 matches the piston diameter. The two large discs have a major diameter of $1.2 \mathrm{~m}$. The disc diameter was chosen to be large to minimize flow momentum in and out of the test section. The tube attached to the left disc in Figure 3 has a length of $0.3 \mathrm{~m}$.

The test section turns the flow $90^{\circ}$ as the piston travels back and forth. The geometry of Fig. 3 was chosen to provide a mathematically "simple" situation for first-cut modeling and code development, yet still complex enough to provide separation zones that challenge the capabilities of the code. The distance between the two large discs is variable from $25 \mathrm{~mm}$ to $127 \mathrm{~mm}$ (1 inch to $5 \mathrm{inch})$.

The primary measurement technique in this study was photographic documentation of streaks made with laser light reflected from helium bubbles. Very briefly, in a sample procedure, a signal processing box is programmed to open the shutter over a 15 degree segment (e.g. $0^{\circ} \leq \vartheta \leq 15^{\circ}$ after top dead center (ATDC)) and to open it at the same time each cycle over 100 cycles. A $35 \mathrm{~mm}$ camera is set up to view the laser light sheet continuously. After 100 cycles, the processing box stops opening the laser shutter and the camera shutter is manually closed. The result is an ensemble-averaged photograph of a $15^{\circ}$ segment of crank angle duration. An example of such a result is presented in Fig. 4 on the right side, for the "channel" field of view defined in Fig. 3. 
CSU used a 2-D axisymmetric CFD-ACE model to calculate turbulent and laminar flow cases for comparison with the flow visualization results. These are also shown in Fig. 4. It can be seen that the turbulent calculation did a better job than the laminar in determining the position of the center of the vortex.

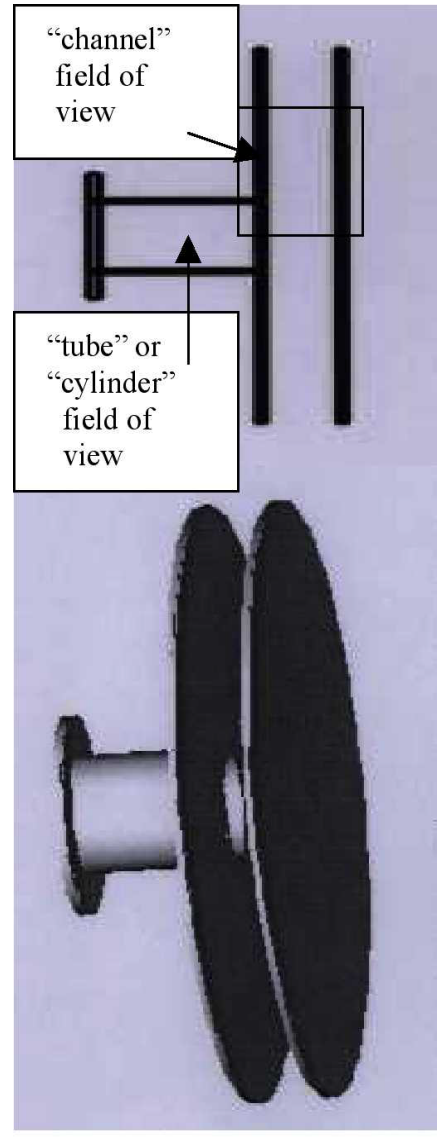

FIGURE 3. Cross-Section of Test Section (above), Solid Model (below)

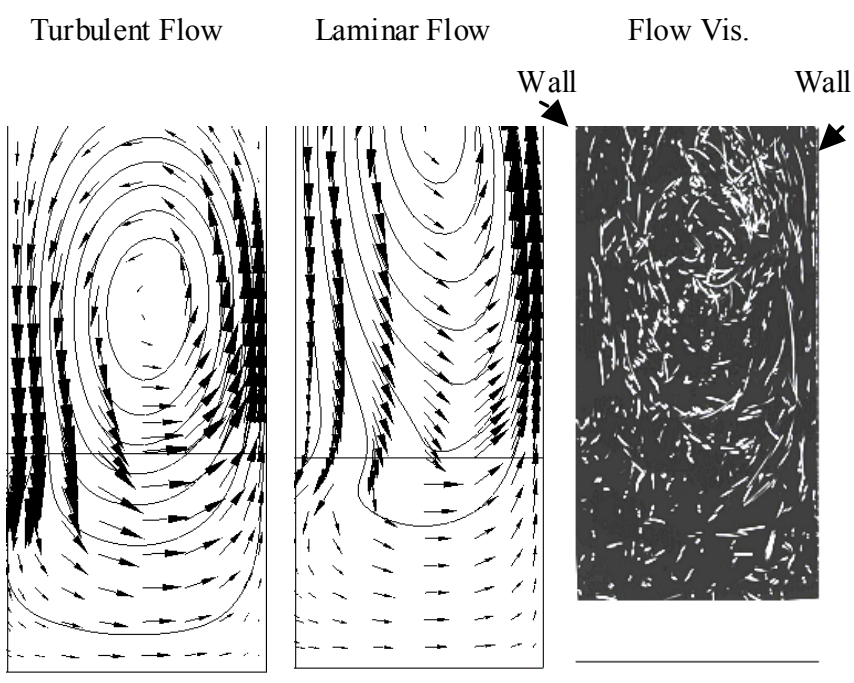

FIGURE 4. Computed Results (CSU) and Flow Visualization $(\mathrm{UMN})$ over $0^{\circ} \leq \theta \leq 15^{\circ}$

A significant feature of this test data, also captured by the CFD calculations, is a large standing vortex (or eddy) between the discs (see Fig. 4). The exhaust stroke serves to energize the eddy whereas the intake stroke simply causes it to move slightly. This standing vortex translates within the test section, but never disappears. The implication is that there is large eddy transport within the space between the two discs. This eddy augments heat and momentum transport within the regions of Stirling engines simulated by this experiment (e.g., the expansion space volume "above" the displacer of the TDC). So, this vortex is of great interest. When the geometry is changed to a narrower disc spacing of $54 \mathrm{~mm}$, the dynamics of the vortex change dramatically. A vortex appears on the exhaust stroke, but it is ingested and destroyed on the intake stroke. Thus, for the aforementioned case, the presumed enhanced momentum and heat transfer due to the standing eddy is active only for one half of the cycle. Thus the geometry of the expansion and compression volumes in a Stirling convertor would have a significant effect on the nature of the vortices that occur in these spaces, and could significantly affect heat and momentum transfer in these variable volumes, and the performance of the convertor. The thermodynamic hysteresis loss in these variable volumes would appear to be the loss most likely to be affected by the characteristics of these vortices. It's also possible that designs calculated to "harness" the heat transfer enhancement effects of these vortices might offer improved performance via design changes that reduce dead volume of a convertor (suggested by Berchowitz, 2002).

There are also interesting phenomena that occur in the "tube" or "cylinder" field of view defined in Fig. 3. For example Fig. 5, taken from Ibrahim (2002), shows a comparison between laminar CFD calculations and flow visualization data for UMN test Case IIIa also discussed in Adolfson (2002) (54 mm disc spacing, 70 RPM, and $72^{\circ} \leq \theta \leq 126^{\circ} A T D C$ ). It should be noted that the CFD calculations are shown from the edge of the tube to the piston head, while the flow visualization is only for a portion of the tube. The flow visualization and CFD results show a separation bubble created downstream of the sharp tube inlet during the suction stroke $\left(0^{\circ} \leq \theta \leq 180^{\circ} A T D C\right)$. More illustrations of the test results are in Adolfson (2002) and more comparisons with CFD results are in Ibrahim (2002a). These results show that the separation bubble grows in the streamwise and cross-streamwise directions as the suction stroke proceeds. It was noted that the laminar CFD calculations did a reasonable job of predicting the center and size of the original separation bubble. However, some other features of 
the data were not predicted, such as (1) the difference in flow direction during different cycles, indicated by the "streak lines" in the lower visualization data of Fig. 5, and (2) turbulence phenomena in the latter part of the suction stroke, since a laminar calculation was run.

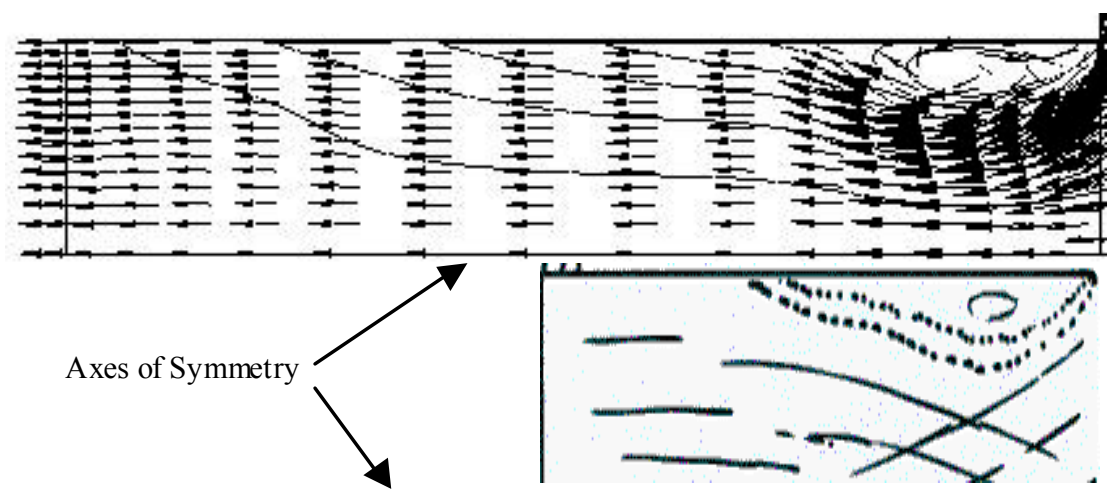

FIGURE 5. Comparison between CSU CFD-ACE Calculations (Top) and UMN Flow Visualization Data for Test Case IIIa (54 mm Disc Spacing, 70 RPM) at $72^{\circ} \leq \theta \leq 126^{\circ} A T D C$

Hot-wire anemometry is now being used to make velocity measurements within the UMN rig. These measurements will allow for a more severe test of the CSU CFD-ACE model calculations. Also, a "180 degree turn" or "180 degree expansion head" test section is being designed for attachment to the UMN scotch yoke drive facility. This new test section will roughly simulate the 180 degree turn flow path from the displacer to, and including, the heater that occurs in current Stirling convertors of interest, like the TDC. Tests with this new test section will include the effects of heat transfer, rather than just being limited to flow phenomena as in the current "90 degree turn" test module. Fabrication of the new test module is expected to be completed, and flow visualization tests are to begin, during the first quarter of 2003.

\section{CSU Stirling Laboratory Research Engine (SLRE) Test Rig}

The CSU SLRE derives from a two-piston Stirling engine developed by NASA Jet Propulsion Laboratory (Hoehn, 1982). It is a higher frequency device than the UMN test rig. The phase angle between the two opposed SLRE pistons is adjustable. A special test section has been designed and fabricated for bolting between the two existing piston-cylinder flanges on the rig. The pistons will drive atmospheric-pressure air or helium through the test section at Reynolds and Valensi numbers representative of Stirling engine practice. Several flow inserts have been designed and fabricated to be representative of regions of Stirling engines where flow area changes abruptly or flow velocity changes direction. The SLRE test section contains a window to permit LDV (laser doppler velocimeter) measurements of velocity. Before making velocity measurements, temperature and pressure measurements will be taken within the test section; these tests are to be completed at CSU by the first quarter of 2003. Also, CFD-ACE simulations of the SLRE tests with various flow inserts will be made for comparison with the data.

\section{COMPLEMENTARY DOE REGENERATOR RESEARCH EFFORT}

A complementary DOE Regenerator Research effort is also providing oscillating-flow and heat-transfer data for validation of CFD-ACE. This work is also aiding in development of regenerator matrix models for the multi-D Stirling code. The purpose of this three year effort (9/1/00-8/31/03) is to do fundamental regenerator research which will lead to improvements in Stirling regenerator, and convertor, performance. It is funded by DOE's Office of Energy Efficiency and Renewable Energy (Goldin, Co.) to advance solar dish-Stirling technology; Lizana Pierce is contract monitor. The team effort is being carried out by CSU (the lead organization, responsible for CFD), UMN (responsible for testing), Gedeon Associates and GRC. Results of the UMN test effort have been reported by Niu (2002; 2003). Results of the corresponding CSU CFD effort have been reported by Ibrahim (2002b).

Fig. 6 shows a schematic of the facility and the test section. The facility consists of an oscillating flow generator, a flow distributor, an air-water cooler, a regenerator, an electrical heater and an isolation duct. The piston is driven by the same scotch yoke driver shown in Fig. 2. The present experiments are run at a frequency of $0.4 \mathrm{~Hz}$, a stroke of $356 \mathrm{~mm}$ and a piston diameter of $356 \mathrm{~mm}$. A detailed description of the test section, including the large-scale regenerator mesh dimensions and arrangement, is given in Niu (2002). The three cooler tubes shown are part of a 


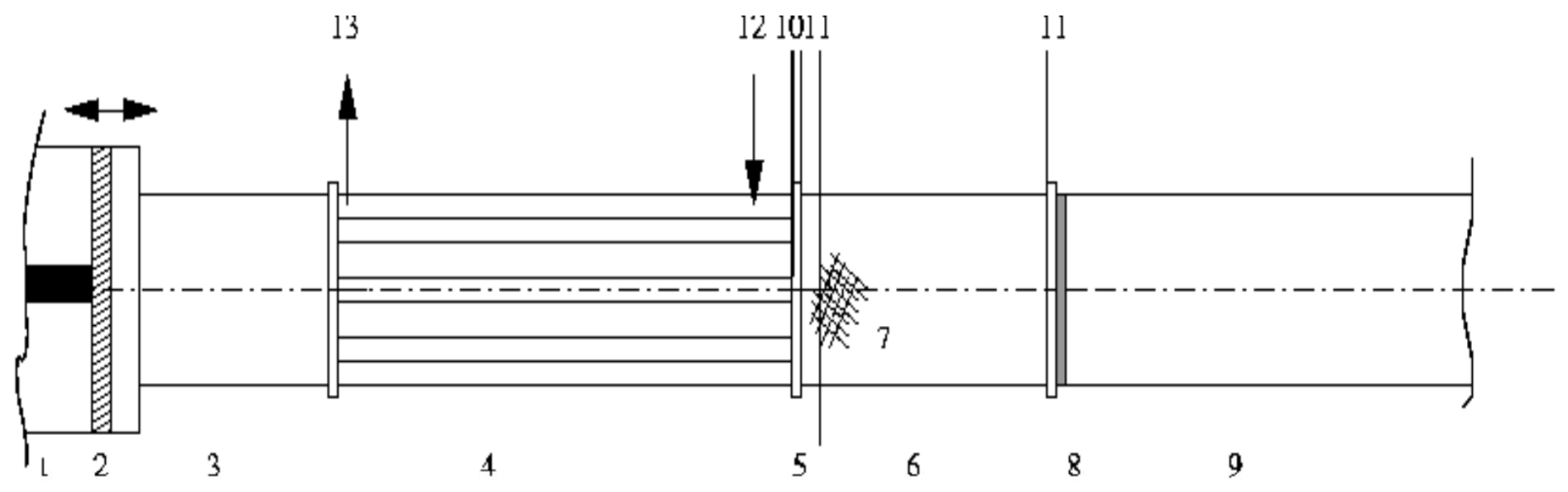

1- oscillating flow genecator, 2 -piston, 3-flow distributor, 4-cooler, 5-plenum, 6-regenerator, 7-screen matrix, 8-electrical heating coil, 9-isolatinn duct, 10-hot-wire, 11 -thermocouple, 12-cooling water in, 13-cooling water out

FIGURE 6. Schematic of the UMN Regenerator Experimental Facility and Test Section

$3 \times 3$ rectangular array. Note the plenum between the cooler tubes and regenerator matrix whose length can be varied to study the effect on jetting of flow from the cooler tubes into the matrix. The regenerator porosity is $90 \%$, similar to that of a number of modern small free-piston Stirling engines. Hot-wire anemometry has been used to measure velocities at the axial center of the plenum and temperatures both within the plenum and within the regenerator matrix. A representative Stirling engine was chosen for definition of test section design dimensionless parameters (e.g., maximum Reynolds number and Valensi number).

Fluid velocities at the axial mid-point of the plenum, taken across the flow paths of the three central cooler tubes, are shown in Fig. 7. The plenum diameter is $190 \mathrm{~mm}$ and width is $6.35 \mathrm{~mm}$. The peaks in velocities are due to jetting flows out of the cooler tubes in Fig. 7a and are due to flow "sinks" into the cooler tubes in Fig. 7b. Thus the flow peaks in Figs. $7 \mathrm{a}$ and $7 \mathrm{~b}$ are actually in opposite directions. The flow at the edges in Fig. $7 \mathrm{a}$ ( 3.5 and -3.5 inches) is thought to be in the opposite direction from the peak flow velocities (hot-wire anemometry velocity measurements do not define the flow direction). This assumption is consistent with CFD-ACE flow computations and also with previous 2-D regenerator/plenum modeling done by Gedeon (1989). This suggests that, as fluid from the cooler tubes "jets" into the matrix, there is flow recirculation so that flow is actually exiting the matrix at the wall. Niu (2003) addresses the fraction of the matrix that is "inactive" due to the jetting of fluid into the matrix. Velocity measurements have been taken for different plenum lengths at UMN, but these are not yet available for reporting. Also, the permeability and the inertial flow coefficient for the test matrix have been measured.

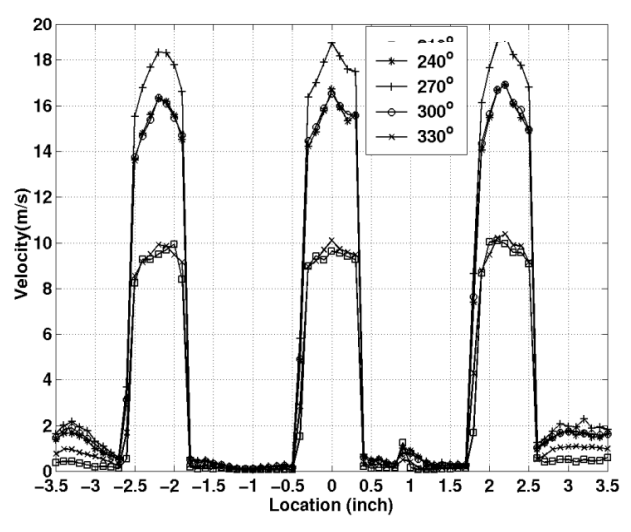

(a) Blowing Half of Cycle

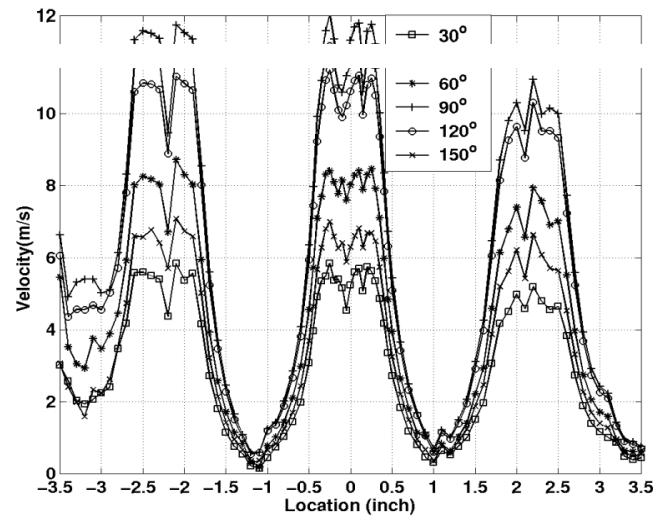

(b) Suction Half of Cycle

FIGURE 7. Velocities at Axial Mid-Point of the Plenum. Angles Shown are After Top-Dead-Center or ATDC. (Suction-Half Velocities are in Opposite Direction from Blowing-Half) 
An initial 2-D CFD model of the UMN flow test section predicted plenum velocities that were in reasonable agreement with the data. A porous media model of the regenerator is being used to simulate velocities in the regenerator. CFD-ACE results (plenum velocities and initial regenerator velocities), generated with a model of the UMN test section for comparison with data, were reported by Ibrahim (2002b).

\section{CONCLUDING REMARKS}

Multi-dimensional Stirling models provide an alternative loss characterization strategy to attempting detailed measurements within small, high-frequency engines. Validation of these models can be approached by use of test sections that are simpler than a complete engine but that incorporate "engine like" flow and heat transfer processes. Multi-D models of these test sections can then be used for CFD-ACE code validation. Addition of thermodynamic $2^{\text {nd }}$ law analysis (entropy, available energy, exergy, etc.), not currently available in CFD-ACE, to post process the multi-D computations would enhance the ability of these multi-D codes to characterize and separate thermodynamic losses.

There are some multi-D code development problems. 2-D models require considerable computer time. 3-D model time requirements are much greater. Assuming these time requirements can be practically addressed by using a parallelized version of CFD-ACE with a cluster of workstations, there are still problems in modeling the fluid-flow and heat-transfer processes that need solution. For example, (1) accurate prediction of turbulence phenomena in an oscillating-flow, oscillating-pressure level, complex geometry environment is not state-of-the-art. This includes the problems of predicting when transitions between laminar and turbulent flow occur (Earlier loss understanding testing at UMN did address laminar-turbulent transition for oscillating flow in a pipe). (2) Even in a nominally axisymmetric geometry, there are usually/frequently small asymmetries that produce non-axisymmetric phenomena. These will not be tracked by an axisymmetric 2-D or a 3-D simulation. (3) In general, the porous media that are used for regenerator matrices have such small flow passages and solid metal dimensions that it is not practical to simulate them exactly; therefore, macroscopic models of the porous media must be used. (4) CSU and CFDRC are working together to solve apparent problems found when the CFD-ACE porous media module was used with one of the available CFD-ACE turbulence models to model oscillating flow in a porous matrix. (5) Thermal relaxation of solid materials is a problem. For example, thermal relaxation time of the regenerator matrix, or wall, can be several orders of magnitude greater than the cycle period. This is a problem unless special means can be devised to accelerate convergence of the solid material temperatures.

\section{REFERENCES}

Adolfson, D.A., Simon, T.W., Ibrahim, M.B., and Gedeon, D., "Measurements in Oscillatory Flows with Separation in Support of Stirling Engine Model Development," Proceedings of the $37^{\text {th }}$ Intersociety Energy Conversion Engineering Conference, Washington, D.C., IECEC 2002 Paper No. 20142, (2002).

Berchowitz, D., Private Communication, 2002.

Gedeon, D., "Modeling 2-D Jets Impinging on Stirling Regenerators," Proceedings of the $24^{\text {th }}$ Intersociety Energy Conversion Engineering Conference, Washington, D.C., Paper No. 899202, (1989).

Gedeon, D., "Sage User's Guide," $3^{\text {rd }}$ Edition, Gedeon Associates, 16922 South Canaan Road, Athens, OH 45701, (1999).

Hoehn, F.W., "Stirling Laboratory Research Engine," JPL Publication 82-13, (1982).

Ibrahim, M.B., Tew, R.C., Zhang, Z., Gedeon, D., and Simon, T.W., "CFD Modeling of Free-Piston Stirling Engines," Proceedings of the $36^{\text {th }}$ Intersociety Energy Conversion Engineering Conference, Savannah, GA, 2001 (IECEC2001-CT-38), NASA/TM -2001-211132, 2001.

Ibrahim, M.B., Zhang, Z., Kembhavi, S., Simon, T.W., and Gedeon, D., “A 2-D Axisymmetric CFD Model of Oscillatory Flow with Separation," Proceedings of the $37^{\text {th }}$ Intersociety Energy Conversion Engineering Conference, Washington, D.C., IECEC 2002 Paper No. 20121, (2002a).

Ibrahim, M.B., Zhang, Z., Wei, R., Simon, T.W. and Gedeon, D., “A 2-D CFD Model of Oscillatory Flow with Jets Impinging on a Random Wire Regenerator Matrix," Proceedings of the $37^{\text {th }}$ Intersociety Energy Conversion Engineering Conference, Washington, D.C., IECEC 2002 Paper No. 20144, (2002b).

Kornhauser, A.A., Gas-Wall Heat Transfer During Compression and Expansion, Massachusetts Institute of Technology, S.D. Thesis, 1989.

Niu, Y., Simon, T.W., Ibrahim, M.B., and Gedeon, D., "Oscillatory Flow and Thermal Field Measurements at the Interface between a Heat Exchanger and a Regenerator of a Stirling Engine," Proceedings of the $37^{\text {th }}$ Intersociety Energy Conversion Engineering Conference, Washington, D.C., IECEC 2002 Paper No. 20141, (2002). 
Niu, Y., Simon, T.W., Ibrahim, M.B., and Gedeon, D., "Thermal Dispersion of Discrete Jets upon Entrance to a Stirling Engine Regenerator under Oscillatory Flow Conditions," Proceedings of the $6^{\text {th }}$ ASME-JSME Thermal Engineering Joint Conference, Hapuna Beach, Hawaii Island, Hawaii, TED-AJ03-641, 2003.

Tew, R.C., "Study of Two-Dimensional Compressible Non-Acoustic Modeling of Stirling Machine Type Components," Proceedings of the $36^{\text {th }}$ Intersociety Energy Conversion Engineering Conference, Savannah, GA, 2001 (IECEC2001-CT-27), NASA/TM -2001-211066, 2001.

Thieme, L.G., Schreiber, J.G., and Mason, L.S., "Stirling Technology Development at NASA GRC," Proceedings of the Space Technology Applications International Forum (STAIF-2002), edited by M.S. El-Genk, AIP Conf. No. 608, AIP, NY, 2002 , NASA/TM-2001-211315/REV1, 2002. 
Public reporting burden for this collection of information is estimated to average 1 hour per response, including the time for reviewing instructions, searching existing data sources, gathering and maintaining the data needed, and completing and reviewing the collection of information. Send comments regarding this burden estimate or any other aspect of this collection of information, including suggestions for reducing this burden, to Washington Headquarters Services, Directorate for Information Operations and Reports, 1215 Jefferson Davis Highway, Suite 1204, Arlington, VA 22202-4302, and to the Office of Management and Budget, Paperwork Reduction Project (0704-0188), Washington, DC 20503.

\begin{tabular}{|l|c|c|}
\hline 1. AGENCY USE ONLY (Leave blank) & $\begin{array}{c}\text { 2. REPORT DATE } \\
\text { December } 2002\end{array}$ & $\begin{array}{c}\text { 3. REPORT TYPE AND DATES COVERED } \\
\text { Technical Memorand }\end{array}$
\end{tabular}

\section{TITLE AND SUBTITLE}

5. FUNDING NUMBERS

Overview of NASA Multi-Dimensional Stirling Convertor Code Development and Validation Effort

\section{AUTHOR(S)}

Roy C. Tew, James E. Cairelli, Mounir B. Ibrahim, Terrence W. Simon, and David Gedeon

\section{PERFORMING ORGANIZATION NAME(S) AND ADDRESS(ES)}

National Aeronautics and Space Administration

John H. Glenn Research Center at Lewis Field

Cleveland, Ohio 44135-3191

WU-755-1A-14-00

\section{SPONSORING/MONITORING AGENCY NAME(S) AND ADDRESS(ES)}

National Aeronautics and Space Administration

Washington, DC 20546-0001

8. PERFORMING ORGANIZATION REPORT NUMBER

E-13669

\section{SUPPLEMENTARY NOTES}

Prepared for the Space Technology and Applications International Forum (STAIF-2003) cosponsored by the American Institute of Aeronautics and Astronautics and the University of New Mexico, Albuquerque, New Mexico, February 2-6, 2003. Roy C. Tew and James E. Cairelli, NASA Glenn Research Center; Mounir B. Ibrahim, Cleveland State University, Cleveland, Ohio 44115; Terrence W. Simon, University of Minnesota, Minneapolis, Minnesota 55455; and David Gedeon, Gedeon Associates, Athens, Ohio 45701. Responsible person, Roy C. Tew, organization code 5490, 216-433-8471.

Unclassified - Unlimited

Subject Categories: 34 and 20

Distribution: Nonstandard

Available electronically at http://gltrs.grc.nasa.gov

This publication is available from the NASA Center for AeroSpace Information, 301-621-0390.

\section{ABSTRACT (Maximum 200 words)}

A NASA grant has been awarded to Cleveland State University (CSU) to develop a multi-dimensional (multi-D) Stirling computer code with the goals of improving loss predictions and identifying component areas for improvements. The University of Minnesota (UMN) and Gedeon Associates are teamed with CSU. Development of test rigs at UMN and CSU and validation of the code against test data are part of the effort. The one-dimensional (1-D) Stirling codes used for design and performance prediction do not rigorously model regions of the working space where abrupt changes in flow area occur (such as manifolds and other transitions between components). Certain hardware experiences have demonstrated large performance gains by varying manifolds and heat exchanger designs to improve flow distributions in the heat exchangers. 1-D codes were not able to predict these performance gains. An accurate multi-D code should improve understanding of the effects of area changes along the main flow axis, sensitivity of performance to slight changes in internal geometry, and, in general, the understanding of various internal thermodynamic losses. The commercial CFD-ACE code has been chosen for development of the multi-D code. This 2-D/3-D code has highly developed pre- and postprocessors, and moving boundary capability. Preliminary attempts at validation of CFD-ACE models of MIT gas spring and "two space" test rigs were encouraging. Also, CSU's simulations of the UMN oscillating-flow rig compare well with flow visualization results from UMN. A complementary Department of Energy (DOE) Regenerator Research effort is aiding in development of regenerator matrix models that will be used in the multi-D Stirling code. This paper reports on the progress and challenges of this multi-D code development effort.

14. SUBJECT TERMS

Stirling cycle; Stirling engines; Simulation; Fluid mechanics; Heat transfer 15. NUMBER OF PAGES 15

\begin{tabular}{|c|c|c|}
\hline $\begin{array}{c}\text { 17. SECURITY CLASSIFICATION } \\
\text { OF REPORT } \\
\text { Unclassified }\end{array}$ & $\begin{array}{c}\text { 18. SECURITY CLASSIFICATION } \\
\text { OF THIS PAGE } \\
\text { Unclassified }\end{array}$ & $\begin{array}{c}\text { 19. SECURITY CLASSIFICATION } \\
\text { OF ABSTRACT } \\
\text { Unclassified }\end{array}$ \\
\hline
\end{tabular}

